\title{
Wafer Bonding of SiC-AlN at Room Temperature for All-SiC Capacitive Pressure Sensor
}

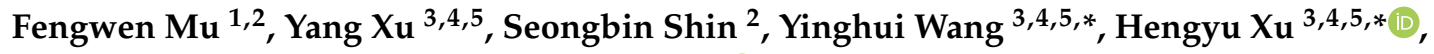

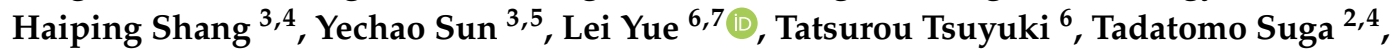 \\ Weibing Wang ${ }^{3,5}$ and Dapeng Chen ${ }^{3,5}$ \\ 1 Kagami Memorial Research Institute for Materials Science and Technology, Waseda University, Shinjuku, \\ Tokyo 169-0051, Japan; mufengwen123@gmail.com \\ 2 Collaborative Research Center, Meisei University, Hino-shi, Tokyo 191-8506, Japan; \\ bin912000@naver.com (S.S.); tadatomo.suga@meisei-u.ac.jp (T.S.) \\ 3 Institute of Microelectronics of Chinese Academy of Sciences, Beijing 100029, China; \\ xuyang@ime.ac.cn (Y.X.); shanghaiping@ime.ac.cn (H.S.); sunyechao@ime.ac.cn (Y.S.); \\ wangweibing@ime.ac.cn (W.W.); dpchen@ime.ac.cn (D.C.) \\ 4 Kunshan Branch, Institute of Microelectronics of Chinese Academy of Sciences, Suzhou 215347, China \\ 5 University of Chinese Academy of Sciences, Beijing 100049, China \\ 6 Institute of Semiconductor \& Electronics Technologies, ULVAC, Inc., Susono 410-1231, Japan; \\ lei_yue@ulvac.com (L.Y.); tatsurou_tsuyuki@ulvac.com (T.T.) \\ 7 ULVAC Research Center Suzhou Co., Ltd., Suzhou 215026, China \\ * Correspondence: wangyinghui@ime.ac.cn (Y.W.); xuhengyu@ime.ac.cn (H.X.)
}

Received: 29 August 2019; Accepted: 18 September 2019; Published: 23 September 2019

check for updates

\begin{abstract}
Wafer bonding of a silicon carbide ( $\mathrm{SiC}$ ) diaphragm to a patterned $\mathrm{SiC}$ substrate coated with aluminum nitride (AlN) film as an insulating layer is a promising choice to fabricate an all-SiC capacitive pressure sensor. To demonstrate the bonding feasibility, a crystalline AlN film with a root-mean-square (RMS) surface roughness less than $\sim 0.70 \mathrm{~nm}$ was deposited on a $\mathrm{SiC}$ wafer by a pulsed direct current magnetron sputtering method. Room temperature wafer bonding of SiC-AIN by two surface activated bonding (SAB) methods (standard SAB and modified SAB with Si nano-layer sputtering deposition) was studied. Standard SAB failed in the bonding, while the modified SAB achieved the bonding with a bonding energy of $\sim 1.6 \mathrm{~J} / \mathrm{m}^{2}$. Both the microstructure and composition of the interface were investigated to understand the bonding mechanisms. Additionally, the surface analyses were employed to confirm the interface investigation. Clear oxidation of the AlN film was found, which is assumed to be the failure reason of direct bonding by standard SAB.
\end{abstract}

Keywords: all-silicon carbide ( $\mathrm{SiC})$; capacitive pressure sensor; room temperature wafer bonding; interface; aluminum nitride (AIN) film

\section{Introduction}

Pressure sensors for harsh environments at high temperature are critical for advanced industrial, automotive, and aerospace sensing applications. Silicon (Si) has been the dominant platform for pressure sensors. However, $\mathrm{Si}$ is susceptible to exposure to corrosive mediums and loss of its mechanical reliability at $773 \mathrm{~K}$ while Si P-N junctions degrade at temperatures above $473 \mathrm{~K}$, and thus, is not suitable for the pressure sensors in harsh environments with high temperature [1-3]. Silicon carbide (SiC) is an excellent candidate material for high-temperature applications because of its wide band-gap, high thermal-mechanical stability, high chemical inertness, and high electrical stability at elevated temperature [3-5]. Many researches have employed a SiC pressure sensing diaphragm on a Si substrate [3-9] but the devices suffer from thermal expansion mismatch between the diaphragm and 
Si substrate. In recent years, all-SiC pressure sensors have been reported but mainly piezo-resistive types [10-13]. Piezo-resistive pressure sensors, however, have a small gage factor and a significant temperature-dependence as well as suffer from contact resistance variation at elevated temperature, which would bring an inferior sensor performance. Capacitive pressure sensors can overcome the stated disadvantages of piezo-resistive pressure sensors, already realized for wireless sensing schemes $[9,14]$. However, reports of all-SiC capacitive pressure sensors are very few. Only L. Chen et al. published an all-SiC capacitive pressure sensor, which is comprised of a $\mathrm{SiC}$ diaphragm on a poly $\mathrm{SiC}$ substrate. The SiC diaphragm was deposited by low pressure chemical vapor deposition and released by a chemical etching process [14].

$\mathrm{SiC}$-diaphragm bonding onto a patterned $\mathrm{SiC}$ substrate coated with an insulating film is another choice to fabricate an all-SiC capacitive pressure sensor, in which the real bonding is between $\mathrm{SiC}$ and the insulating layer. The SiC-diaphragm wafer could be a 3C-SiC epi-layer grown on a Si substrate or a $\mathrm{SiC}$ layer transferred on a support substrate. A simplified schematic illustration of the above proposal is shown in Figure 1. For the insulating layer between diaphragm and substrate, there are several choices such as $\mathrm{Si}_{3} \mathrm{~N}_{4}, \mathrm{SiO}_{2}$, and $\mathrm{AlN}$. Compared to $\mathrm{Si}_{3} \mathrm{~N}_{4}$ and $\mathrm{SiO}_{2}, \mathrm{AlN}$ shows a long-term high-temperature stability and a similar thermal expansion coefficient as that of $\mathrm{SiC}$, which means the reduction of error and failure owing to the small thermal expansion mismatch between diaphragm and substrate [15-18].

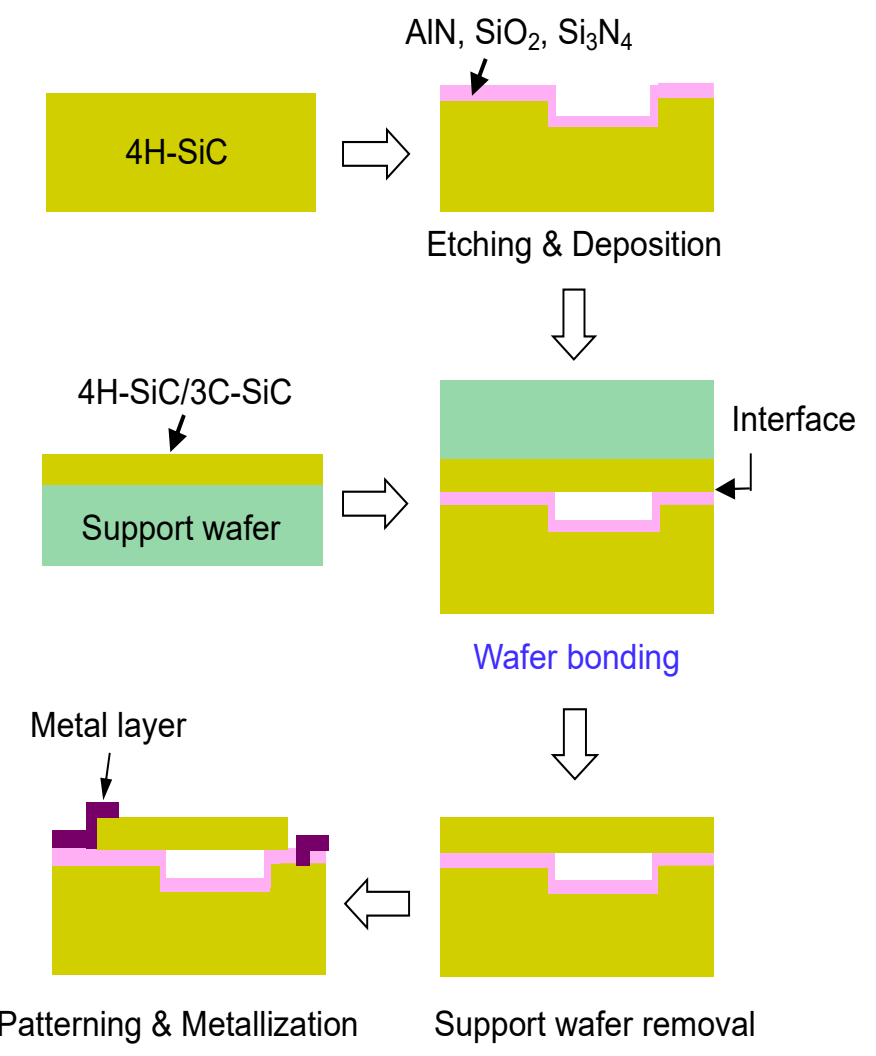

Figure 1. A simplified schematic process to fabricate the all-silicon carbide ( $\mathrm{SiC})$ capacitive pressure sensor via wafer bonding.

To our best knowledge, the bonding of $\mathrm{SiC}$ to AlN is hardly reported; thus, it is worth to demonstrate the wafer bonding of $\mathrm{SiC}$ to AlN. In this study, an AlN film is deposited on a $\mathrm{SiC}$ substrate for the bonding demonstration of SiC-AlN. A second SiC wafer, same as that for AlN deposition, is used as the SiC-diaphragm wafer. Prior to bonding, the deposited AlN film is inspected by dynamic force microscopy (DFM) and scanning electron microscopy (SEM). After bonding, the bonded wafer is characterized in terms of bonding void and bonding energy. Further, the bonding mechanisms are 
investigated through interfacial analyses using scanning transmission electron microscopy (STEM) and electron energy loss spectroscopy (EELS). In addition, surface analysis using X-ray photoelectron spectroscopy (XPS) is carried out to confirm the interfacial analyses.

\section{Materials and Methods}

A 100 nm-thick AlN film was deposited on the Si-face of a commercial 4H-SiC substrate (4-inch, $\sim 355$ - $\mu$ m-thick, n-type, $4^{\circ}$ off towards [11-20]) by a pulsed direct current magnetron sputtering machine (ULVAC SME-200) for bonding demonstration. Pure $\mathrm{N}_{2}$ gas was used for the sputtering and the background vacuum of the sputtering chamber was $1 \times 10^{-5} \mathrm{~Pa}$. The Si-face used for deposition was smoothed by chemical mechanical polishing (CMP) to achieve an RMS surface roughness of $\sim 0.3 \mathrm{~nm}$. Before the AlN deposition in wafer size, an optimization process to reduce the surface roughness was conducted in chip size $(10 \mathrm{~mm} \times 10 \mathrm{~mm})$ by controlling the substrate temperature. In the temperature range from $573 \mathrm{~K}$ to $973 \mathrm{~K}$, the higher the temperature, the smaller surface roughness. Therefore, the deposition for bonding was carried out at a substrate temperature of $973 \mathrm{~K}$ to get a smooth surface, which is critical to get a successful bonding at a low temperature. After deposition, the surface roughness and microstructure of the AIN film were investigated by DFM and SEM. Here, a second 3-inch SiC wafer, same as that for deposition, was used as the SiC-diaphragm wafer for the bonding demonstration.

Surface activated bonding method was employed for bonding of $\mathrm{SiC}$ to $\mathrm{AlN}$ at room temperature, which could avoid any thermal damages or residual stress caused by thermal expansion mismatch when the real thin SiC film would be used. Both standard SAB and modified SAB with Si nano-layer sputtering deposition were applied to realize the bonding of SiC-AlN. Since Si-Si bonding by SAB can be as strong as bulk material [19], the Si nano-layer in modified SAB is expected to enhance the bonding. The standard SAB process consists of two steps: firstly, the wafer surfaces are activated by the Ar ion beam irradiation with the accelerating voltage and current of $1 \mathrm{kV}$ and $100 \mathrm{~mA}$, respectively; secondly, after surface activation, the two activated wafers are contacted directly under $1.0 \mathrm{MPa}$ for $300 \mathrm{~s}$ at room temperature in ultra-high vacuum (UHV). The modified SAB with Si nano-layer sputtering deposition contains four steps: the first is also surface activation but followed by Si sputtering deposition via Ar ion beam on both wafers; then surface activation of the Si deposited layers is done; finally, the bonding is conducted under $\sim 1.0 \mathrm{MPa}$ for $300 \mathrm{~s}$ in UHV. The accelerating voltage of the ion beam source for both surface activation and sputtering deposition is $1 \mathrm{kV}$, and the currents of the ion beam source for surface activation and sputtering deposition are $200 \mathrm{~mA}$ and $400 \mathrm{~mA}$, respectively. After bonding, the bonded wafer was characterized in terms of bonding void and bonding energy by scanning acoustic microscope (SAM) with a pixel size of $50 \mu \mathrm{m}$ and by crack-opening method. In the crack-opening method [20,21], a razor blade is inserted to measure the bonding energy $(\gamma)$ in air at room temperature, which is the fracture energy of bonding interface. Since the thickness of the AlN layer could be neglected compared with that of the $\mathrm{SiC}$ substrate, the two wafers are considered as same substrate. Therefore, the bonding energy is calculated by the following equation [20]:

$$
\gamma=\frac{3 t_{\mathrm{b}}^{2} \mathrm{E} t_{\mathrm{w}}^{3}}{32 L^{4}}
$$

where $\mathrm{E}=530 \mathrm{GPa}$ is selected as the Young's modulus of single crystalline $4 \mathrm{H}-\mathrm{SiC}$ [22], $t_{\mathrm{w}}$ is the thickness of wafer, $t_{\mathrm{b}}$ is the thickness of blade, and $L$ is the crack length. To understand the bonding mechanism, the microstructure and composition of the bonding interface were investigated by STEM and EELS. To confirm the results of STEM and EELS, different sample surfaces were further analyzed by XPS with an Al X-ray source $(1486.6 \mathrm{eV})$. 


\section{Results and Discussion}

The RMS surface roughness of the AlN layer deposited on a SiC chip at temperature of $973 \mathrm{~K}$ can be $\sim 0.55 \mathrm{~nm}$, as shown in Figure 2a. When the AlN deposition is conducted in wafer size, the wafer center can have a similar RMS surface roughness as in chip size while that of wafer edge areas is $\sim 0.64 \mathrm{~nm}$. Figure $2 \mathrm{~b}$ shows the cross-sectional SEM image of the AlN on SiC. The film has a uniform thickness of about $100 \mathrm{~nm}$. Additionally, the AlN layer consists of numerous highly-oriented columnar grains, perpendicular to the surface of SiC substrate, which are very likely along the $c$-axis (0002) orientation. Similar structure has been found in previous researches [23-25].

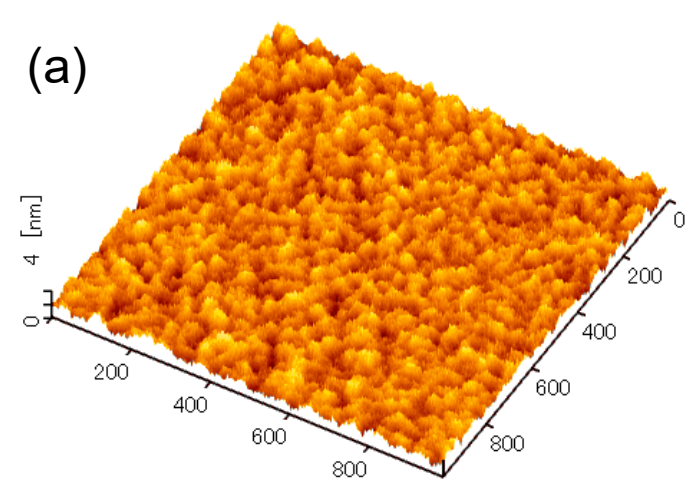

$[\mathrm{nm}]$

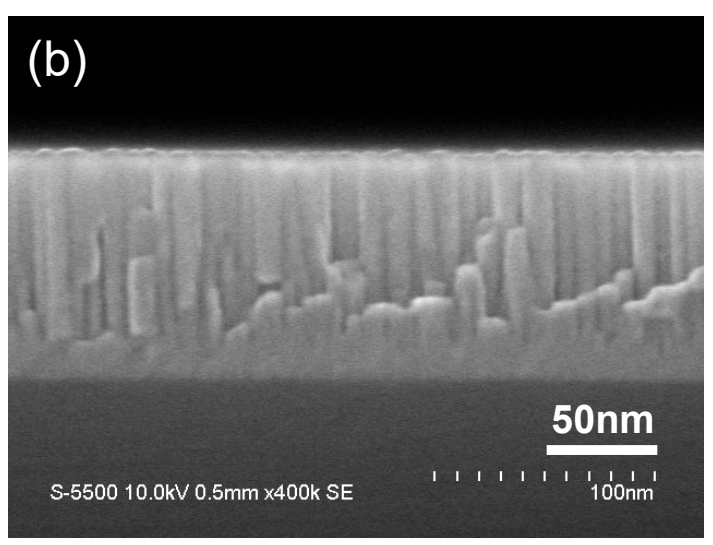

Figure 2. (a) Dynamic force microscopy (DFM) image of the surface $(1 \mu \mathrm{m} \times 1 \mu \mathrm{m})$ of aluminum nitride (AlN) film (in chip size) deposited at a substrate temperature of $973 \mathrm{~K}$ and (b) cross-sectional scanning electron microscopy (SEM) image of the AlN layer deposited on SiC.

The bonding energy of SiC-AlN by standard SAB and modified SAB with Si nano-layer sputtering deposition is compared in Figure 3a. The bonding of SiC to AlN by standard SAB fails, while modified SAB can achieve a successful bonding with a bonding energy of $\sim 1.6 \mathrm{~J} / \mathrm{m}^{2}$. The SAM image of the bonded wafer by modified SAB is illustrated in Figure $3 b$, which shows that most of the wafer is bonded except some voids and the edge exclusion area. The ratios of the voids area and the edge exclusion area are $\sim 5 \%$ and $\sim 10 \%$, respectively. According to our experiences, the voids are formed by particle contaminations since the bonding experiments were not carried out in a clean room. Experimental operation in cleanroom can reduce the voids area. 

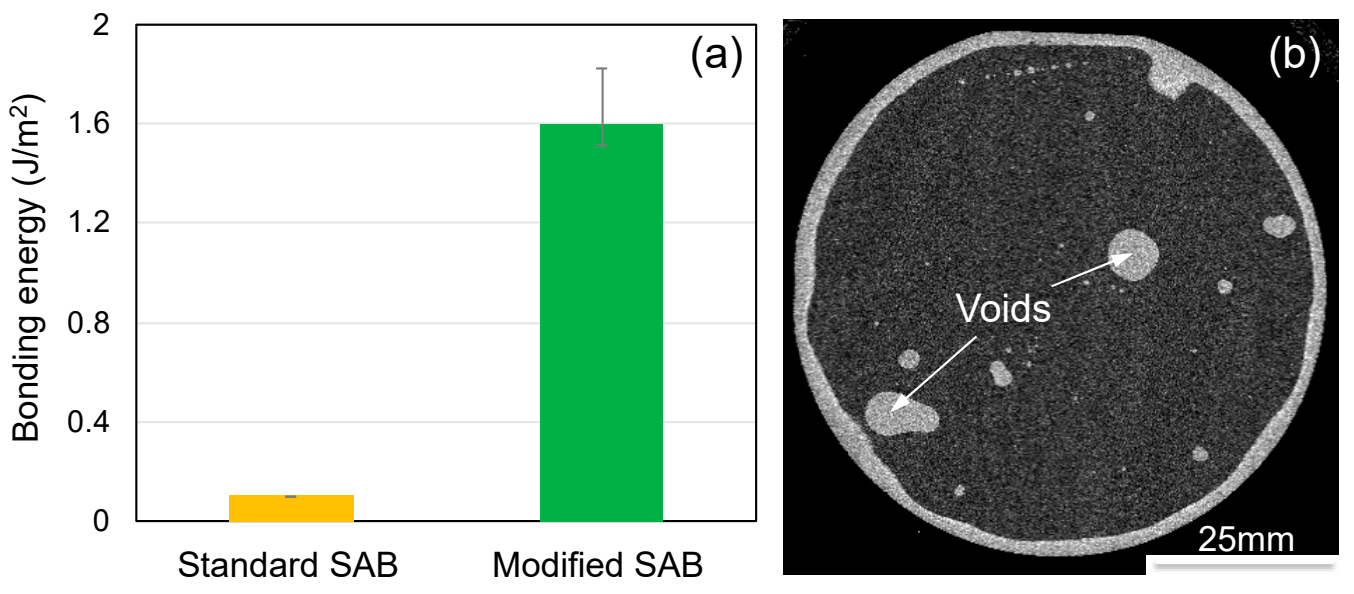

Figure 3. (a) Comparison of bonding energy of SiC-AlN using standard surface activated bonding (SAB) and modified SAB with Si nano-layer sputtering deposition and (b) scanning acoustic microscope (SAM) image of the bonded wafer of SiC-AlN.

To understand the bonding mechanisms and the failure of standard SAB, STEM and EELS were employed to analyze the microstructure and composition of the bonding interface and the AlN surface layer. Figure 4a shows the structure of SiC-AlN-SiC. No clear voids or cracks are seen. The thickness of the deposited AlN layer is in agreement with the measurements in the SEM examination mentioned above. The rectangular area in Figure $4 \mathrm{a}$ is further magnified to show the interfacial structure, as displayed in Figure $4 \mathrm{~b}$. There is a seamless amorphous layer with a thickness of $\sim 15 \mathrm{~nm}$ at the bonding interface of SiC-AlN. According to our previous researches [26,27], the surface activation of ion beam bombardment will cause the formation of amorphous layer. Therefore, the amorphous layer may consist of amorphous $\mathrm{SiC}$, amorphous $\mathrm{AlN}$, and deposited Si layer. The total thickness of the two deposited Si layers is around 10nm according to our previous measurement. Besides, lattice structure can be observed on the AlN side, which confirms that the deposited AlN has a crystalline structure. The result of EELS scanning along the white line in Figure 4a is shown in Figure 5. The profiles of Si, C, $\mathrm{Al}, \mathrm{N}$, and $\mathrm{O}$ are represented by green, black, blue, purple, and red. The interfacial Si layer can be clearly identified, and the deposited AlN film is N-enriched to some extent. The surface layer of AlN after surface activation seems still $\mathrm{N}$-enriched. It is noteworthy that $\mathrm{O}$ is detected in both of the surface layer and the inside of deposited AlN film, which indicates the oxidization of AlN during deposition. This oxidation may be the cause of the failure of the direct bonding with standard SAB. This is in agreement with earlier observations of the weak bonding of $\mathrm{SiC}$ to oxide using standard SAB [28].

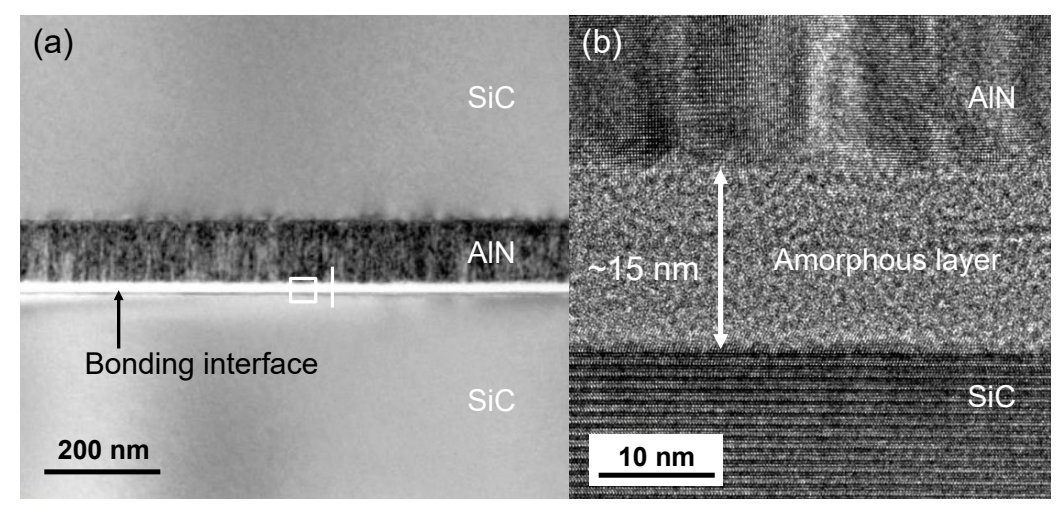

Figure 4. (a) Scanning transmission electron microscopy (STEM) image of the bonded SiC-AlN interface at a low magnification and (b) the magnification of the rectangular area in (a). 


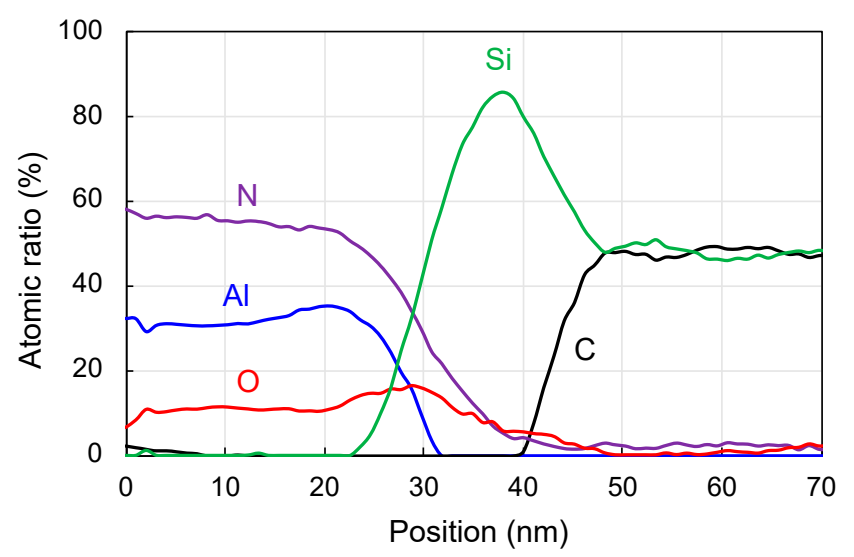

Figure 5. Electron energy loss spectroscopy (EELS) scanning along the white line in Figure 4a. The profiles of $\mathrm{Si}, \mathrm{C}, \mathrm{Al}, \mathrm{N}$, and $\mathrm{O}$ are represented by green, black, blue, purple, and red.

To confirm the uniformity of deposited Si layer and the oxidation of AIN film, XPS spectra, as shown in Figure 6, are taken from four different surfaces: AlN film coated with $\sim 5 \mathrm{~nm}$ Si layer (used for bonding in modified SAB), AlN film, AlN film after $\sim 50 \mathrm{~nm}$ etching by ion beam equipped in XPS analysis chamber, and exposed $\mathrm{SiC}$ substrate after the complete etching of AlN film. The $\mathrm{C} 1 \mathrm{~s}$ peak position of the adventitious carbon at $284.8 \mathrm{eV}$ is used as the charge reference. According to the XPS spectra taken from the AlN film coated by $\sim 5 \mathrm{~nm}$ Si layer, no Al can be detected from the AlN layer, which indicates the uniform deposition of Si layer. By comparison of the XPS results of both the AlN film and the AlN film after $\sim 50 \mathrm{~nm}$ etching, the oxidation can be clearly confirmed from $\mathrm{O} 1 \mathrm{~s}$ spectra. Moreover, their Al $2 \mathrm{p}$ peak positions have visible difference. The Al $2 \mathrm{p}$ peak of the AlN film locates at $\sim 74.1 \mathrm{eV}$, agreeing with the published data [29], while the peak of the etched AlN film is shifted towards the peak of Al-O at $75.0 \mathrm{eV}$ [30]. This further confirms the oxidation of AlN during deposition, and the internal AlN seems more seriously oxidized. Very interestingly, both $\mathrm{N} 1 \mathrm{~s}$ peaks of the two samples are at $\sim 397.0 \mathrm{eV}$ with a symmetrical shape, which implies they are likely from AlN [29]. Besides, no N-O peak is found in the $\mathrm{N} 1$ s spectra [31], which does not exhibit the existence of $\mathrm{N}-\mathrm{O}$. One possible $\mathrm{O}$ source might be the inside of $\mathrm{SiC}$ substrate; however, the spectra of the $\mathrm{SiC}$ after complete etching of AlN film confirms that there is no O inside SiC. The relative low background vacuum of the chamber may cause the oxidation of AlN film during deposition at a high temperature. This may be avoided by the improvement of the background vacuum of the chamber in the future. 

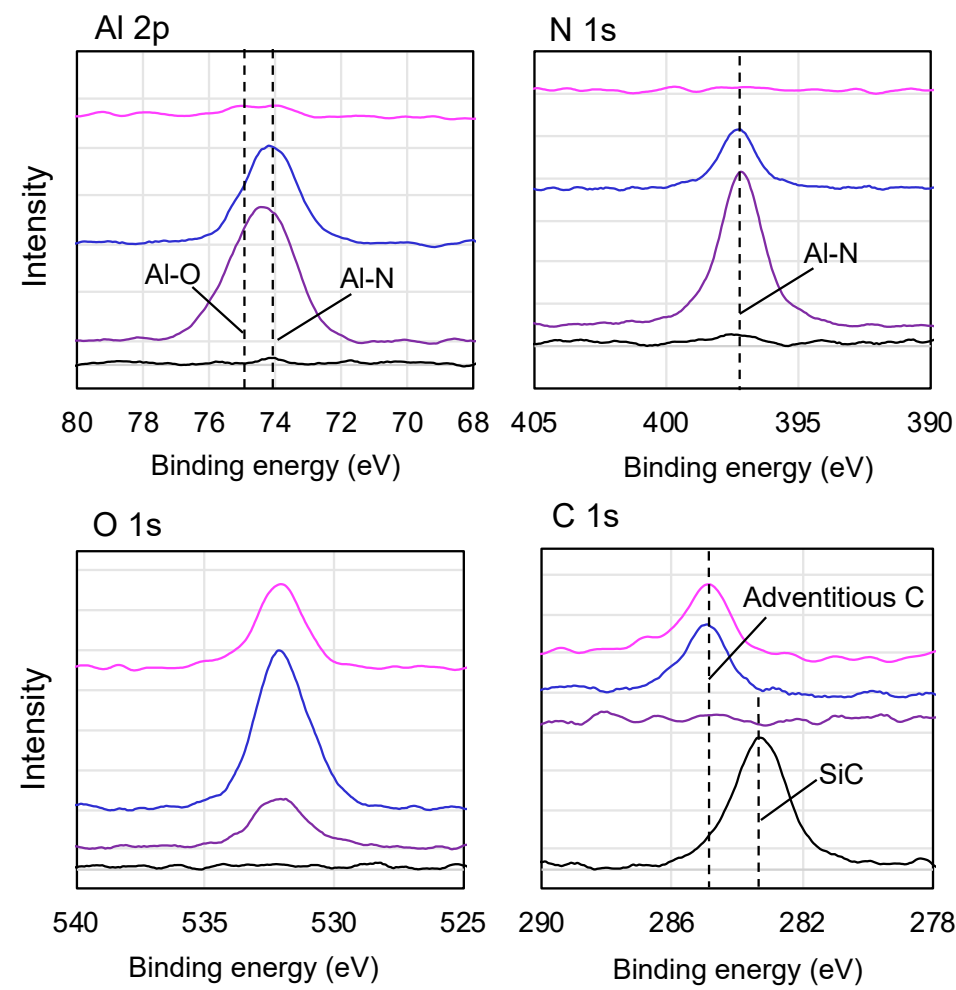

C 1s

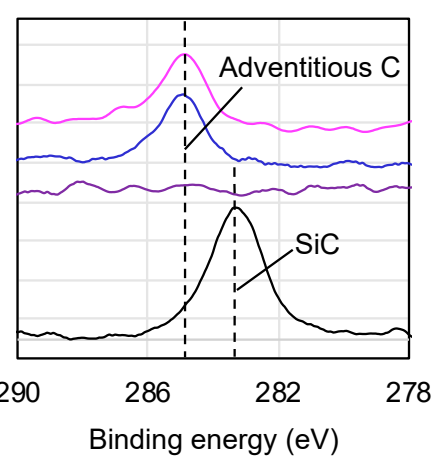

AIN coated by $\sim 5 \mathrm{~nm} \mathrm{Si}$
AIN surface

AIN after $\sim 50 \mathrm{~nm}$ ion etching

Exposed $\mathrm{SiC}$ after removing AIN

Figure 6. X-ray photoelectron spectroscopy (XPS) spectra of $\mathrm{Al} 2 \mathrm{p}, \mathrm{N} 1 \mathrm{~s}, \mathrm{O}$ 1s, and $\mathrm{C} 1 \mathrm{~s}$ taken from AlN film coated with $\sim 5 \mathrm{~nm}$ Si layer (used for bonding in modified SAB), AlN film, the AlN film after $\sim 50 \mathrm{~nm}$ etching by ion beam, and exposed $\mathrm{SiC}$ substrate after the complete etching of AlN, which are highlighted by magenta, blue, purple, and black.

\section{Conclusions}

Wafer bonding of SiC-AlN for the fabrication of all-SiC capacitive pressure sensor is proposed and demonstrated in this study. For bonding demonstration, a crystalline AlN film with a thickness of $\sim 100 \mathrm{~nm}$ and an RMS surface roughness less than $\sim 0.7 \mathrm{~nm}$ was deposited on a $\mathrm{SiC}$ wafer by a pulsed direct current magnetron sputtering method at a substrate temperature of $973 \mathrm{~K}$. Both standard SAB and modified SAB with Si nano-layer sputtering deposition were applied to the SiC-AlN bonding at room temperature. Standard SAB failed in the bonding, while the bonding using modified SAB had a bonding energy of $\sim 1.6 \mathrm{~J} / \mathrm{m}^{2}$, which is strong enough to withstand common mechanical cutting process [27]. The microstructure and composition of the bonding interface were investigated by STEM and EELS. A $\sim 15 \mathrm{~nm}$ amorphous layer was observed at the interface, which consisted of amorphous $\mathrm{SiC}$, amorphous AlN and deposited Si nano-layer. The N-enrichment of AlN film was confirmed, which can explain why the surface layer of AlN after surface activation seemed N-enriched. Notably, the oxidation was detected in the AIN side. Surface analyses by XPS further confirmed the AIN oxidation and the uniformity of the deposited Si nano-layer in the modified SAB method. The AIN oxidation was considered to be a possible failure reason of the direct bonding with standard SAB.

Author Contributions: Conceptualization, F.M., Y.W., and T.S.; methodology, F.M., Y.X., S.S., H.S., Y.S., L.Y., T.T.; investigation, F.M., Y.W., and Y.S.; writing-original draft preparation, F.M., Y.X., and S.S.; writing-review and editing, F.M., Y.X., S.S., L.Y., H.X., and Y.W.; project administration, Y.W., H.X., T.S., W.W., and D.C.; funding acquisition, Y.W., W.W., and D.C.

Funding: This research was funded by the "100 Talents Project" of Chinese Academy of Sciences under Grant No. Y6YB02F001.

Conflicts of Interest: The authors declare no conflict of interest. 


\section{References}

1. Phan, H.-P.; Dao, D.V.; Nakamura, K.; Dimitrijev, S.; Nguyen, N.-T. The piezoresistive effect of SiC for MEMS sensors at high temperatures: A review. J. Microelectromech. Syst. 2015, 24, 1663-1677. [CrossRef]

2. Jones, D.G.; Jog, A.V.; Jamshidi, B.; Myers, D.R.; Chen, L.; Fu, X.; Mehregany, M.; Wijesundara, M.B.J.; Pisano, A.P. A SiC MEMS resonant strain sensor for harsh environment Applications. IEEE Sens. J. 2007, 7, 568-576.

3. Marsi, N.; Majlis, B.Y.; Mohd-Yasin, F.; Hamzah, A.A. The fabrication of back etching 3C-SiC-on-Si diaphragm employing $\mathrm{KOH}+$ IPA in MEMS capacitive pressure sensor. Microsyst. Technol. 2015, 21, 1651-1661.

4. Young, D.J.; Du, J.; Zorman, C.A.; Ko, W.H. High-temperature single-crystal 3C-SiC capacitive pressure sensor. IEEE Sens. J. 2004, 4, 464-470. [CrossRef]

5. Du, J.; Ko, W.H.; Mehregany, M.; Zorman, C.A. Poly-SiC capacitive pressure sensors made by wafer bonding. In Proceedings of the IEEE Sensors, Irvine, CA, USA, 30 October-3 November 2005; pp. 1267-1270.

6. Wu, C.-H.; Zorman, C.A.; Mehregany, M. Fabrication and testing of bulk micromachined silicon carbide piezoresistive pressure sensors for high temperature applications. IEEE Sens. J. 2006, 6, 316-324.

7. Liu, L.; Tang, W.; Zheng, B.; Zhang, H. Fabrication and characterization of SiC thin films. In Proceedings of the 2011 6th IEEE International Conference on Nano/Micro Engineered and Molecular Systems, Kaohsiung, Taiwan, 20-23 February 2011; pp. 146-149.

8. Xie, S.; Savu, V.; Tang, W.; Vazquez-Mena, O.; Sidler, K.; Zhang, H.; Brugger, J. Robust PECVD SiC membrane made for stencil lithography. Microelectron. Eng. 2011, 88, 2790-2793.

9. Du, J.; Zorman, C.A. A polycrystalline SiC-on-Si architecture for capacitive pressure sensing applications beyond $400{ }^{\circ} \mathrm{C}$ : Process development and device performance. J. Mater. Res. 2013, 28, 120-128. [CrossRef]

10. Wieczorek, G.; Schellin, B.; Obermeier, E.; Fagnani, G.; Drera, L. SiC based pressure sensor for high-temperature environments. In Proceedings of the 2007 IEEE Sensors, Atlanta, GA, USA, 28-31 October 2007; pp. 748-751.

11. Okojie, R.S. Stable $600{ }^{\circ} \mathrm{C}$ silicon carbide MEMS pressure transducers. In Proceedings of the Sensors and Systems for Space Applications, Orlando, FL, USA, 9-13 April 2007; p. 65550V.

12. Akiyama, T.; Briand, D.; de Rooij, N.F. Piezoresistive n-type $4 \mathrm{H}-\mathrm{SiC}$ pressure sensor with membrane formed by mechanical milling. In Proceedings of the 2011 IEEE Sensors, Limerick, Ireland, 28-31 October 2011; pp. 222-225.

13. Okojie, R.S.; Lukco, D.; Nguyen, V.; Savrun, E. $4 \mathrm{H}-\mathrm{SiC}$ piezoresistive pressure sensors at $800{ }^{\circ} \mathrm{C}$ with observed sensitivity recovery. IEEE Electron Device Lett. 2015, 36, 174-176. [CrossRef]

14. Chen, L.; Mehregany, M. A silicon carbide capacitive pressure sensor for in-cylinder pressure measurement. Sens. Actuat. A Phys. 2008, 145, 2-8.

15. Griffin, B.A.; Habermehl, S.D.; Clews, P.J. Development of an aluminum nitride-silicon carbide material set for high-temperature sensor applications. Proceedings of the Sensors for Extreme Harsh Environments 1130A.

16. Wang, W.; Liang, J.; Ruan, Y.; Pang, W.; You, Z. Design and fabrication of an surface acoustic wave resonator based on AlN/4H-SiC material for harsh environments. J. Zhejiang Univ. Sci. A 2017, 18, 67-74. [CrossRef]

17. Lv, H.; Yu, H.; Hu, G. A SiC high-temperature pressure sensor operating in severe condition. TELKOMNIKA Indones. J. Electr. Eng. 2012, 10, 2247-2252. [CrossRef]

18. Lv, H.J.; Yu, H.Y.; Hou, J.H.; Geng, T. A study of a silicon carbide capacitive pressure sensor applied in harsh environment. Appl. Mech. Mater. 2013, 241, 984-987.

19. Takagi, H.; Kikuchi, K.; Maeda, R.; Chung, T.R.; Suga, T. Surface activated bonding of silicon wafers at room temperature. Appl. Phys. Lett. 1996, 68, 2222-2224.

20. Maszara, W.P.; Goetz, G.; Caviglia, A.; McKitterick, J.B. Bonding of silicon wafers for silicon-on-insulator. J. Appl. Phys. 1988, 64, 4943-4950. [CrossRef]

21. Plößl, A.; Gertrud, K. Wafer direct bonding: tailoring adhesion between brittle materials. Mater. Sci. Eng. R Rep. 1999, 25, 1-88. [CrossRef]

22. Zhao, F.; Du, W.; Huang, C.-F. Fabrication and characterization of single-crystal $4 \mathrm{H}-\mathrm{SiC}$ microactuators for $\mathrm{MHz}$ frequency operation and determination of Young's modulus. Microelectron. Eng. 2014, 129, 53-57.

23. Singh, A.V.; Chandra, S.; Bose, G. Deposition and characterization of c-axis oriented aluminum nitride films by radio frequency magnetron sputtering without external substrate heating. Thin Solid Films 2011, 519, 5846-5853. [CrossRef] 
24. Thedsakhulwong, A.; Locharoenrat, K.; Thowladda, W. Structure and piezoelectric properties of aluminum nitride thin films on quartz substrates deposited by reactive RF-magnetron sputtering. Adv. Mater. Res. 2013, $699,308-313$.

25. Jackson, N.; Keeney, L.; Mathewson, A. Flexible-CMOS and biocompatible piezoelectric AlN material for MEMS applications. Smart Mater. Struct. 2013, 22, 115033.

26. Mu, F.; Iguchi, K.; Nakazawa, H.; Takahashi, Y.; Fujino, M.; Suga, T. Direct wafer bonding of SiC-SiC by SAB for monolithic integration of SiC MEMS and electronics. ECS J. Solid State Sci. Technol. 2016, 5, 451-456. [CrossRef]

27. Mu, F.; Iguchi, K.; Nakazawa, H.; Takahashi, Y.; Fujino, M.; He, R.; Suga, T. A comparison study: Direct wafer bonding of SiC-SiC by standard surface-activated bonding and modified surface-activated bonding with Si-containing Ar ion beam. Appl. Phys. Express 2016, 9, 081302. [CrossRef]

28. Mu, F.; Iguchi, K.; Nakazawa, H.; Takahashi, Y.; Fujino, M.; He, R.; Suga, T. Room temperature $\mathrm{SiC}_{-} \mathrm{SiO}_{2} \mathrm{wafer}$ bonding enhanced by using an intermediate Si nano Layer. ECS J. Solid State Sci. Technol. 2017, 6, 227-230. [CrossRef]

29. Taylor, J.A.; Rabalais, J.W. Reaction of $\mathrm{N}_{2}{ }^{+}$beams with aluminum surfaces. J. Chem. Phys. 1981, 75, $1735-1745$. [CrossRef]

30. Di Castro, V.; Polzonetti, G.; Contini, G.; Cozza, C.; Paponetti, B. XPS study of $\mathrm{MnO}_{2}$ minerals treated by bioleaching. Surf. Interface Anal. 1990, 16, 571-574. [CrossRef]

31. Asahara, R.; Nozaki, M.; Yamada, T.; Ito, J.; Nakazawa, S.; Ishida, M.; Ueda, T.; Yoshigoe, A.; Hosoi, T.; Shimura, T.; et al. Effect of nitrogen incorporation into Al-based gate insulators in AlON/AlGaN/GaN metal-oxide-semiconductor structures. Appl. Phys. Express 2016, 9, 101002.

(C) 2019 by the authors. Licensee MDPI, Basel, Switzerland. This article is an open access article distributed under the terms and conditions of the Creative Commons Attribution (CC BY) license (http://creativecommons.org/licenses/by/4.0/). 